\title{
Hydrodynamics of the continuously filtering slurry reactor-Influence of load of solids and particle size distribution
}

\author{
P. Huizenga, ${ }^{*}$ J. A. M. Kuipers and W. P. M. van Swaaij \\ Department of Chemical Engineering. Twente University of Technology, PO Box 217. \\ 7500 AE. The Netherlands
}

(Accepted 1 July 1997)

\begin{abstract}
Internal filtration in slurry bubble columns offers a possible solution to the filtration problems related to this reactor type. The applicability of the concept has already been demonstrated at full-scale for waste water treatment. Theoretical description of internal filtration is lacking, however.

In previous work it was derived on basis of two different models, that in three-phase filtration solids concentration in the vicinity of the filter should uniquely depend on a single dimensionless number, i.e.

$$
\varepsilon_{s, h}^{*}=f\left(\frac{J \sqrt{\nu_{l}}}{d_{p} \sqrt{U_{q} g}}\right) .
$$

The validity of the so-called cake build-up number was demonstrated by determining filter cake resistance as an indirect measure of solids concentration for a system in batch operation with respect to solids.

In the present work the force balance model is extended to include the effect of particle size distribution. It is demonstrated that particle polydispersity can explain trends observed upon variation of load of solids, which cannot be understood assuming the particles to be monodispersed. Based on a simplified version of the model including particle polydispersity, a novel diameter characteristic to filtration behaviour of polydisperse solids is derived. Using this novel diameter in the cake build-up number, experimental results for four different size distributions can be reasonably well described by a single master curve. r 1997 Elsevier Science Ltd
\end{abstract}

Kelwords: Slurry; bubble columns; three-phase reactors; filtration: particle size distribution; cut-off diameter.

\section{INTRODLCTIOY}

In slurry bubble columns a gas, a liquid and a solid are brought into intense contact. Usually the applied solid particles are small $(<200 \mu \mathrm{m})$, leading to a strenuous liquid-solid separation for processes involving a liquid product (e.g. hydroxylamine formation in the DSM HPO process, Fischer-Tropsch synthesis). Internal filtration in these cases eliminates the necessity to pump slurry to an external filtration section. Furthermore, when filtering inside the slurry reactor, turbulence induced by rising gas bubbles can be used to keep the filters clean.

Internal filtration has already reached commercial scale application in sewage sludge treatment (Kraft

*Corresponding author. Tel.: 0031534892890 ; fax: 0031534894774. and Mende, 1995). Application of internal filtration in Fischer-Tropsch synthesis has been the subject of some patents (Rytter et al., 1994; Jager et al., 1994). Liquid solid separation is in all cases claimed to be facilitated by gas flow-driven turbulence.

In our previous study the hydrodynamics of threephase filtration were studied both experimentally and theoretically (Huizenga et al., 1997). It was derived both from a surface renewal model and a force balance model that solids concentration in the vicinity of the filter should uniquely depend on a single dimensionless number. On the basis of experiments in which cake resistance was determined as an indirect measure of solids concentration, the validity of the novel dimensionless number could be demonstrated. In our previous experiments glass beads possessing a narrow size distribution were used, while in the models monodispersity was assumed. In practice, broad particle size distributions often occur, which may lead to anomalous behaviour. The present article therefore 
treats the influence of particle polydispersity on threephase filtration hydrodynamics.

\section{THEORY}

\subsection{Force balance model}

Consider a single particle in the vicinity of a filter in a three-phase system. In the Stokes regime the drag force exerted on the particle due to permeate flow can be formulated as

$$
F_{D}=3 \pi \eta_{1} d_{p} J\left(1-\varepsilon_{s, b}\right)^{-4.7} .
$$

According to the above equation the drag force acting on an isolated particle is corrected for the presence of other particles as described by Wen and $\mathrm{Yu}$ (1966). Turbulent fluctuations due to the passage of bubbles in the vicinity of the filter cause a resuspension force counteracting the drag force, where the expression for the former force is given by

$$
F_{R}=\frac{1}{4} \pi d_{p}^{2} \rho_{l}\left(u^{\prime}\right)^{2} .
$$

Following Davies (1986), the fluctuation velocity of the eddies responsible for particle resuspension can be formulated as

$$
u^{\prime}=\frac{(E i)^{1: 3}}{1+x \varepsilon_{s, b}} .
$$

The denominator in the above equation corrects for turbulence damping due to the presence of particles. Huizenga et al. (1997) showed that in three-phase filtration for particles in the size range of interest, the Kolmogoroff-scale $\dot{\lambda}_{k}$ is the length scale characteristic to the resuspending eddies, where $\lambda_{k}$ can be obtained from

$$
i_{i k}=\left(\frac{v_{s l, b}^{3}}{E}\right)^{1: 4}
$$

where as the expression for the energy dissipation rate per unit mass is given by

$$
E=U_{g} g
$$

Kinematic viscosity of the liquid-solid suspension was calculated from the following expression due to Deckwer et al. (1980):

$$
v_{s l . b}=v_{l} \frac{1+4.5 \varepsilon_{s, b}}{1+\left(\frac{\rho_{s}}{\rho_{l}}-1\right) \varepsilon_{s, b}} .
$$

At hydrodynamic equilibrium the aforementioned forces balance, leading to

$$
\frac{J \sqrt{v_{l}}}{d_{p} \sqrt{U_{g} g}}=\frac{1}{12\left(1-\varepsilon_{s, b}^{*}\right)^{-4.7}\left(1+\alpha \varepsilon_{s, b}^{*}\right)^{2}}\left(\frac{v_{s l, b}^{*}}{v_{l}}\right)^{1 / 2}
$$

where the right-hand side of this equation depends only on $\varepsilon_{s, b}^{*}$. Thus, solids holdup in the vicinity of the filter is determined by the dimensionless number appearing in the left-hand side termed cake build-up number and density ratio $\left(\rho_{s} / \rho_{l}\right)$. The latter only enters the equation through kinematic slurry viscosity and its effect can be neglected for the low solids concentrations considered in the present study.

\subsection{Cut-off diameter}

For a polydisperse solid phase one can immediately conclude from eq. (7) that equilibrium can only be attained for a single diameter in the size range concerned, termed the cut-off diameter. Particles possessing a smaller size than the cut-off diameter will deposit on the filter, since drag force is proportional to particle diameter, while resuspension force is proportional to diameter squared. On the other hand, particles possessing a size exceeding the cut-off diameter will remain suspended. In crossflow microfiltration, Foley et al. (1995) successfully described the influence of particle polydispersity using a cut-off diameter concept.

\subsection{Stratified cake build-up}

If in a set of three-phase filtration experiments gas velocity is gradually reduced to its steady-state value as in the experimental procedure followed, cut-off diameter will gradually increase, leading to stratified cake build-up with particle size increasing with distance to the filter (Fig. 1). Assuming a perfectly stratified cake, its resistance $R_{c}$ for a certain (steadystate) cut-off diameter can be calculated from the particle size probability density function using the Kozeny-Carman equation

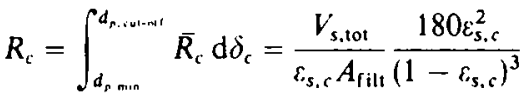

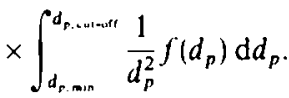

Since for a perfectly stratified cake every layer consists of monodisperse particles, cake solidity is assumed to

\section{Permeate Flux}

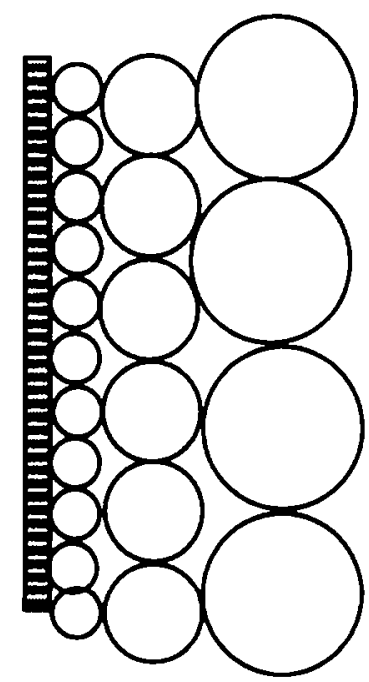

Fig. 1. Schematic drawing of a perfectly stratified filter cake. 
be constant in the above derivation. The maximum cake resistance due to perfectly stratified cake buildup of a certain batch of particles can thus be calculated by inserting the series diameter into the Kozeny Carman equation:

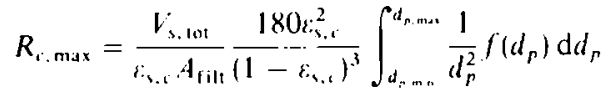

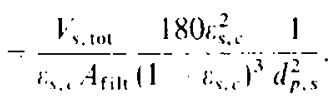

In the above equations, a finite size range for the particles is assumed, as frequently occurs in practice. The ratio of actual and maximum cake resistance (cake ratio) plays an important role in the interpretation of experiments. For a perfectly stratified cake this quantity can he calculated solely from particle size distribution and cut-off diameter. The expression for the cake ratio $(C R)$ is given by

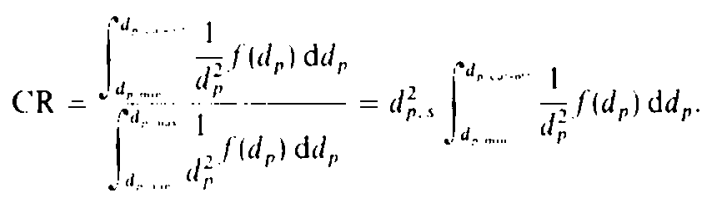

Resistance diameter is now defined as the cut-off diameter at which the resistance attains half of its maximum value:

$$
\int_{d_{1, \ldots}, d_{p}}^{d_{r}} \frac{1}{d_{p}^{2}} f\left(d_{p}\right) \mathrm{d} d d_{p}=\frac{1}{2} \frac{1}{d_{p, s}^{2}}
$$

\subsection{Step function model}

If one neglects the effect of solids concentration in the equilibrium condition [eq. (7)], the right-hand side reduces to 1:12. It follows that if the cake build-up number based on a certain particle size is below or above that critical value. all particles of this particular size will be suspended and deposited. respectively. Consequently, if the resistance diameter is substituted in the dimensionless number for every particle size distribution applied. the critical dimensionless numbers for that diameter coincide. Additionally, assuming perfectly stratified cake build-up, it follows that at this eritical value cake ratio attains the value 0.5 by definition [eqs. (10) and (11)]. Therefore, based on the assumptions given curves of cake ratio vs cake buildup number should intersect at $C R=0.5$ if one inserts resistance diameter in the cake build-up number. In practice. the effect of solids concentration cannot be neglected. However, if the effect of concentration is dominated by the effect of particle polydispersity the assumptions given may still hold to a large extent.

\subsection{Polydisperse filtering slurry hubble column model}

The extended force balance model including cut-off diameter and perfectly stratified cake build-up is embedded in a model describing hydrodynamics of the rectangular filtering slurry bubble column used in the experiments (Fig. 2). This column is equipped with two filters in parallel at a certain axial position, where. depending on imposed conditions $\left(U_{y}, J, r_{1}\right)$, load of solids $\left(M_{\mathrm{s}, \mathrm{tol}}\right)$ and particle size distribution. a cake of solids may form. Cake ratio should be calculated as a function of the variables mentioned to allow comparison with experiments. Since this quantity is completely determined by cut-off diameter [eq. (10)], it suffices to determine the latter for every set of conditions. If one assumes a certain value for cut-off diameter. the corresponding equilibrium value of solids holdup can be determined from the equilibrium condition [eq. (7)] by bisection at the interval $[0,6,$.$] .$ The mass of solids that would be present in the slurry bulk can then be calculated as will be discussed. By integration of the probability density function the mass of solids that would be present in the filter cake follows:

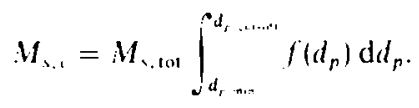

If at a certain cut-off diameter the sum of the masses of solids that would be present in cake and bulk amounts to more or less than total load of solids. cut-off diameter should, respectively. be decreased or increased. Using bisection at the interval $\left[d_{p, \min }, d_{p, \max }\right]$ cut-off diameter is determined with an accuracy of $10{ }^{5}$ relative 10 interval width. Prior to the iteration process, all occurring integrals concerning size distribution are calculated over the full size range using Simpson's rule $(N=10,000)$ and storing equidistant intermediate results $(N=1000)$. During iterations. integrals containing an arbitrary upper houndary are calculated by linear interpolation of the intermediate results.

The mass of solids that would be present in the slurry bulk for a certain equilibrium valuc of solids concentration is calculated from

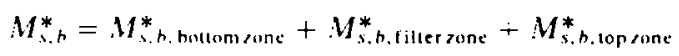

$$
\begin{aligned}
& =\rho, u_{s, h}^{*}\left(1 \quad u_{a, \text { buttom zane }}^{*}\right)
\end{aligned}
$$

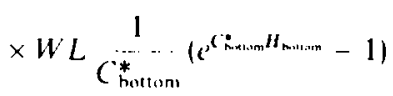

$$
\begin{aligned}
& +\rho_{s} s_{, b}^{*}\left(1-\varepsilon_{4, \text { filter zonc }}^{*}\right) W L H_{\text {filter }} a_{r}^{*}
\end{aligned}
$$

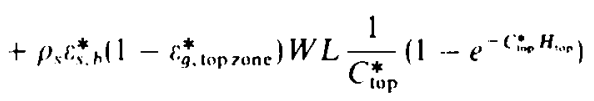

$$
\begin{aligned}
& C_{\text {botrom }}=\frac{u_{p}-u_{1}}{D_{\text {ax.. }}} ; \quad C_{\text {top }}=\frac{u_{p}}{D_{\text {ax.. }}}
\end{aligned}
$$

The above equation is based on integration of the solids concentration profile over the total slurry height. At the position of the filters axial variations are neglected. while a sedimentation-dispersion (SD) model is applicd to the regions above (top) and below the filter zone (bottom). The bulk volume of the slurry in the filter zone is corrected for cross-sectional area reduction due to cake formation [Fig. 2(b)]:

$$
a_{h}-\frac{W-2 j_{c}}{W}
$$




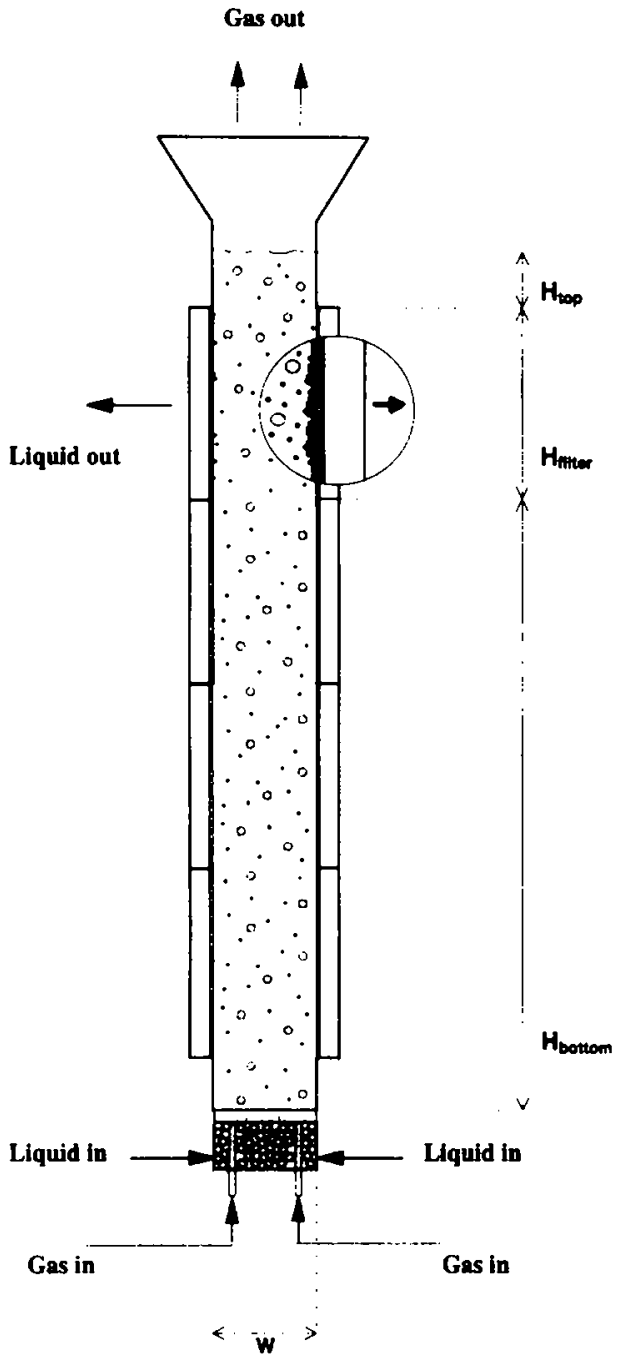

(a)
W-2א

$\leftarrow \cdots>$

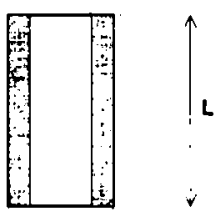

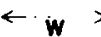

(b)

Fig. 2. Sketch of the filtering slurry bubble column used in the experiments: (a) front view of the column; (b) top view of the filter zone.

Further details concerning the derivation of eq. (13) can be found in Huizenga et al. (1977).

The SD model was extended to include the influence of particle size distribution by Smith et al. (1986). Since the equilibrium condition (7) however only requires total solids concentration, it is decided to use the well-established equations for axial dispersion coefficient $\left(D_{\mathrm{ax}, \mathrm{s}}\right)$ and sedimentation velocity $\left(u_{p}\right)$ by Kato et al. (1972). In these equations, volume-average diameter of the particles that would be present in the slurry bulk is substituted:

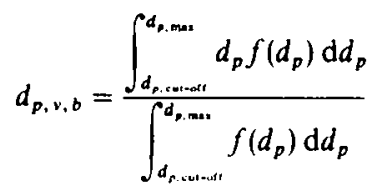

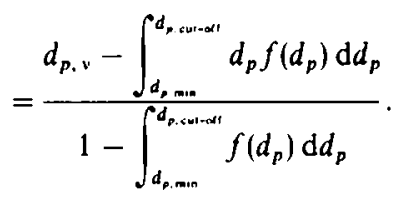

Finally, the required value for gas holdup is obtained from the equation given by Darton (1984).

\section{EQUIPMENT AND EXPERIMENTAL PROCEDURE}

The experiments were performed in a rectangular perspex slurry bubble column $(W=25 \mathrm{~mm}$; $L=50 \mathrm{~mm}$ ) possessing filters $(L=50 \mathrm{~mm})$ of $488 \mathrm{~mm}$ length on two parallel sides, at $40 \mathrm{~mm}$ distance from the bottom. In axial direction the permeable area was divided into four equally sized parts by dams of $8 \mathrm{~mm}$ height leaving $116 * 50 \mathrm{~mm}^{2}$ permeable area per part. Each part had its own collection compartment 


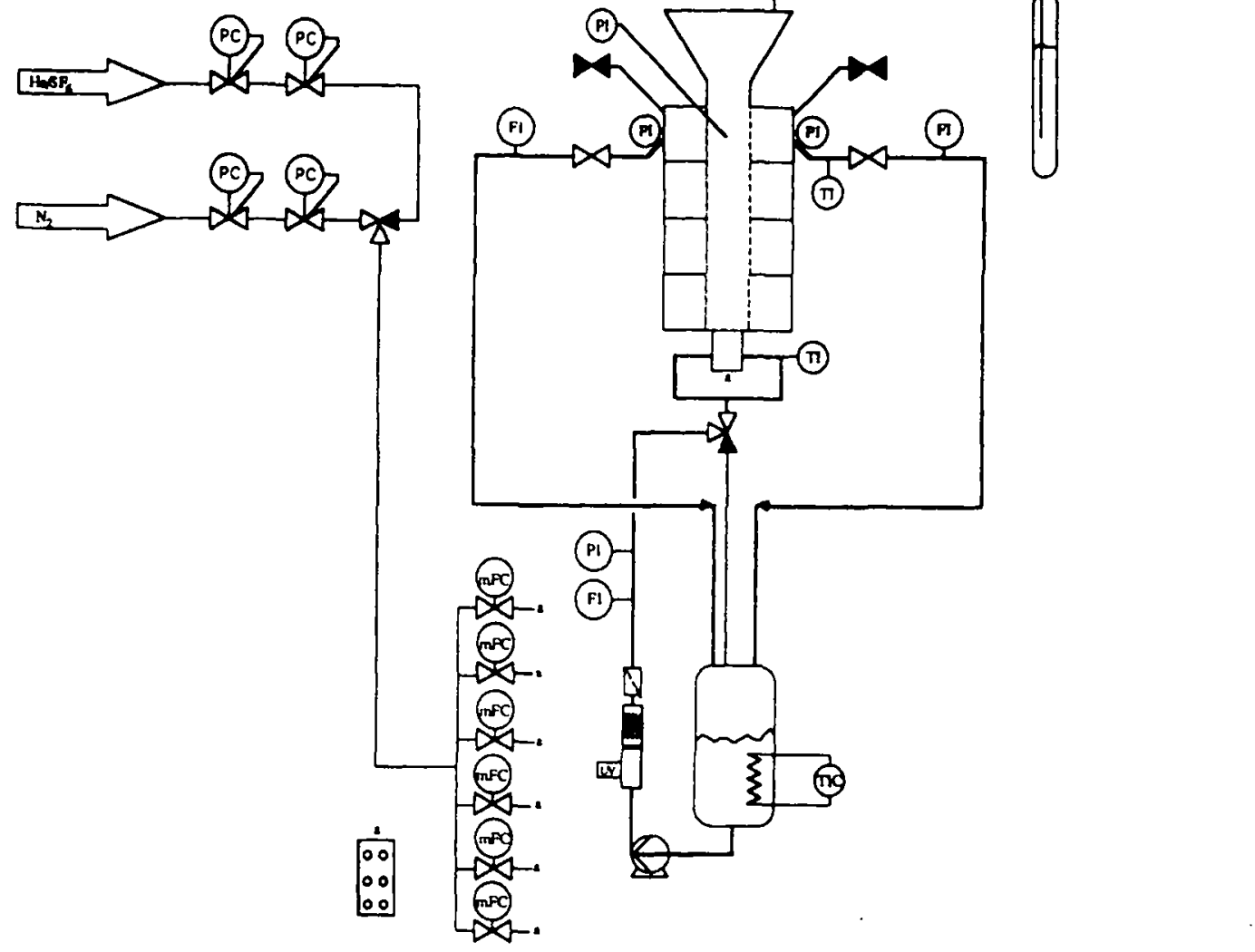

Fig. 3. Flowscheme of the experimental set-up.

equipped with a liquid outlet at the bottom, a pressure indication point at half-height and a deaeration outlet at the top. At the half-height of each compartment the back wall of the column was equipped with pressure indication points covered with $165 \times 1400$ mesh wire gauze to prevent solids discharge from the column. During the experiments reported in this study only the left and the right top compartment were used $\left(H_{\text {bottom }}=412 \mathrm{~mm} ; H_{\text {filter }}=116 \mathrm{~mm}\right)$. A flow scheme of the experimental set-up is shown in Fig. 3. For further details concerning the set-up the interested reader is referred to Huizenga et al. (1997).

Weighed amounts $(10-60 \mathrm{~g})$ of glass beads $\left(\rho_{s}=2890 \mathrm{~kg} \mathrm{~m}^{-3}\right)$ were added to the column via the removable top section. For each batch of solids part of this study, the cumulative size distribution function was measured using a Leeds and Northrup Microtrac X-100 Particle Analyzer. Measured data were subsequently fitted to a particle size distribution of the following form (Peleg et al., 1986):

$$
F\left(d_{p}\right)=\int_{d_{p, \min }}^{d_{r}} f\left(d_{p}\right) \mathrm{d} d_{p}=\int_{0}^{z} f(z) \mathrm{d} z
$$

with

$z=\frac{d_{p}-d_{p, \min }}{d_{p, \max }-d_{p, \min }}, f\left(d_{p}\right)=\frac{1}{d_{p, \max }-d_{p, \min }} f(z)$ and

$$
f(z)=\frac{\frac{z-z^{2}}{z-z^{2}+0.001} \mathrm{e}^{\left.-\left((z) \mu_{i}\right) \cdot c_{i}\right)}}{\int_{0}^{1} \frac{z-z^{2}}{z-z^{2}+0.001} \mathrm{e}^{\left.-\left(1 z-\mu_{i}\right) \cdot c_{i}\right)}} .
$$

An example of a fitted particle size distribution function is presented in Fig. 4, while fitted parameter values $\left(\mu_{z}, C_{z}\right)$ for the applied batches of particles can be found in Table 1. From the available batches of particles, mixtures possessing a volume-average diameter of about $57 \mu \mathrm{m}$ were made. Mass fractions of applied mixtures of these batches can be found in Table 2. The mixture termed 'broad size distribution' was in fact a bimodal batch of particles, which was fitted as a sum of two probability density functions. The probability density function of all mixtures can be calculated by (weighed) superposition. From these functions the diameters characterizing the mixtures were calculated (Table 3). Finally, for the mixtures applied probability density was calculated from measured cumulative size distribution data (Fig. 5).

Experiments were performed both in the absence and the presence of particles. From the experiments 


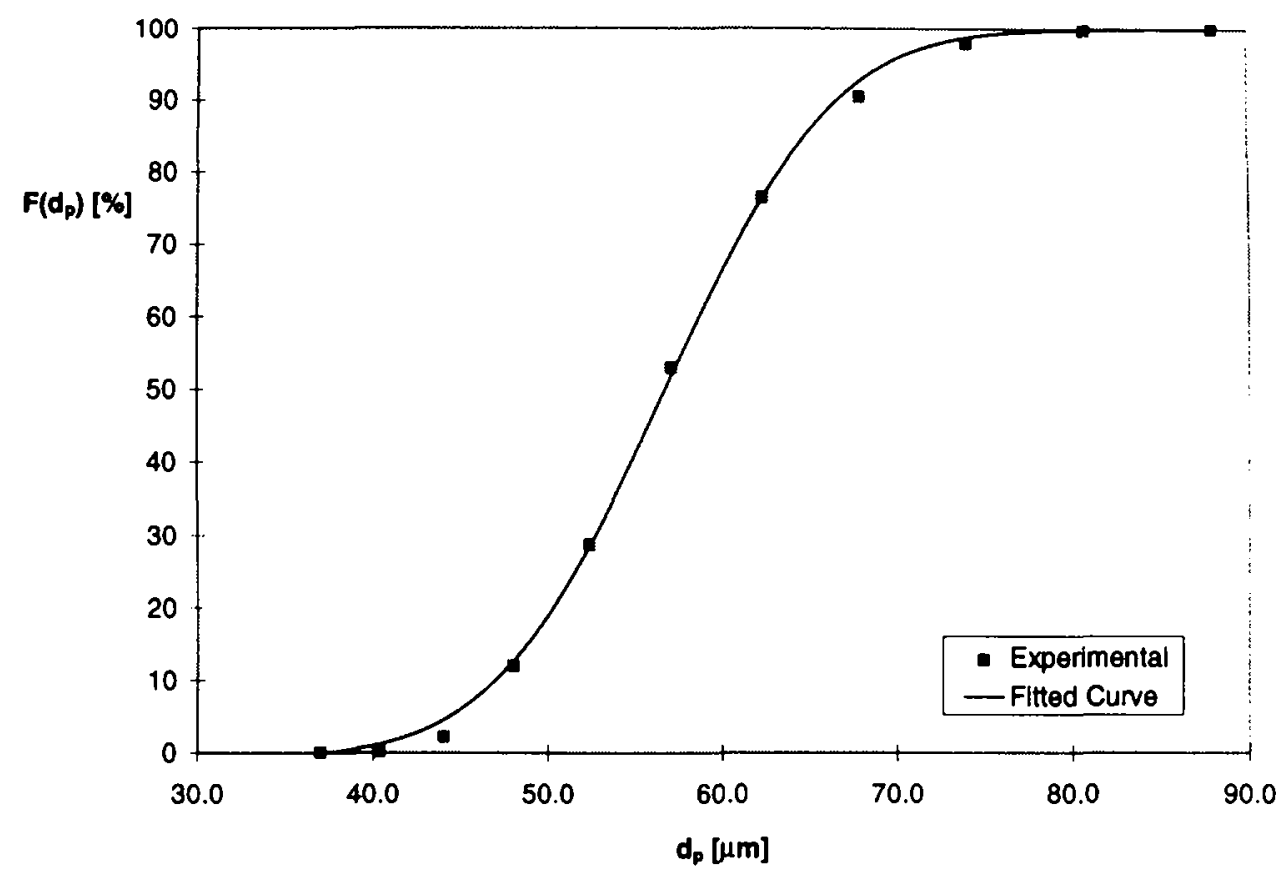

Fig. 4. Experimental and fitted cumulative particle size distribution function for average size $57 \mu \mathrm{m}$ particles possessing a narrow' size distribution.

Table 1. Parameters characterizing particle size distribution of applied batches

\begin{tabular}{lccccc}
\hline & I & II & III & IV & V \\
\hline$d_{p, \min }(\mu \mathrm{m})$ & 37.00 & 37.00 & 88.00 & 40.35 & 22.00 \\
$d_{p, \max }(\mu \mathrm{m})$ & 52.33 & 88.00 & 114.10 & 104.70 & 44.00 \\
$\mu_{z}$ & 0.214724 & 0.385162 & 0.303882 & 0.371355 & 0.456928 \\
$C_{z}$ & 0.256660 & 0.214767 & 0.188339 & 0.254026 & 0.333106 \\
\hline
\end{tabular}

Table 2. Weight fractions of applied mixtures of batches

\begin{tabular}{lcccc}
\hline $\begin{array}{c}\text { Narrow size } \\
\text { distribution }\end{array}$ & Binary mixture & Ternary mixture & $\begin{array}{c}\text { Broad size } \\
\text { distribution }\end{array}$ \\
\hline$x_{1}$ & 0 & 0.7108 & 0.4025 & 0 \\
$x_{\mathrm{II}}$ & 1.0000 & 0 & 0.4337 & 0 \\
$x_{\mathrm{III}}$ & 0 & 0.2892 & 0.1638 & 0 \\
$x_{\mathrm{IV}}$ & 0 & 0 & 0 & 0.7739 \\
$x_{\mathrm{V}}$ & 0 & 0 & 0 & 0.2261 \\
\hline
\end{tabular}

Table 3. Diameter values characteristic of applied mixtures

\begin{tabular}{lcccc}
\hline & $\begin{array}{c}\text { Narrow size } \\
\text { distribution }\end{array}$ & Binary mixture & Ternary mixture & $\begin{array}{c}\text { Broad size } \\
\text { distribution }\end{array}$ \\
\hline$d_{p, r}(\mu \mathrm{m})$ & 56.78 & 56.88 & 56.84 & 57.46 \\
$d_{p, a}(\mu \mathrm{m})$ & 55.75 & 48.95 & 51.69 & 51.40 \\
$d_{p, s}(\mu \mathrm{m})$ & 55.23 & 46.66 & 49.86 & 48.05 \\
$d_{p, s}(\mu \mathrm{m})$ & 54.57 & 40.68 & 42.57 & 38.21 \\
\hline
\end{tabular}

in a clear system, i.e. in the absence of particles, filter resistance could be determined. In the experiments with particles present, the sum of filter and cake resistance was measured keeping the level of the gassed slurry at $589 \mathrm{~mm}\left(H_{\text {top }}=61 \mathrm{~mm}\right)$. Details of measurement principles and procedure can be found in Huizenga et al. (1997), while the range of experimental conditions studied can be found in Table 4 . 
Table 4. Range of experimental conditions

\begin{tabular}{lcccccccc}
\hline Variable & $\begin{array}{c}U_{q}^{\prime} \\
\left(\mathrm{cm}_{i}^{\prime} \mathrm{s}\right)\end{array}$ & $\begin{array}{c}J \\
(\mathrm{~mm} / \mathrm{s})\end{array}$ & $\begin{array}{c}U_{l} \\
(\mathrm{~cm} / \mathrm{s})\end{array}$ & $\begin{array}{c}d_{p, r} \\
(\mu \mathrm{m})\end{array}$ & $\begin{array}{c}y_{1} \\
\left(10^{-} \mathrm{m}^{2} / \mathrm{s}\right)\end{array}$ & $\begin{array}{c}T \\
(\mathrm{C})\end{array}$ & $\begin{array}{c}M_{\mathrm{s}} \\
(\mathrm{g})\end{array}$ & $\begin{array}{l}\varepsilon_{\text {s,avg }} \\
(\%)\end{array}$ \\
\hline Minimum & 0.10 & 0.83 & 0.77 & 57 & 7.99 & 29 & 10.0 & 0.47 \\
Maximum & 3.50 & 2.15 & 2.00 & 57 & 8.16 & 30 & 60.0 & 2.82 \\
\hline
\end{tabular}

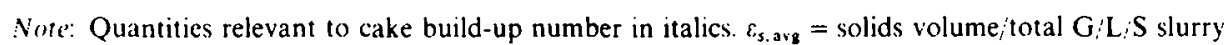
volume.
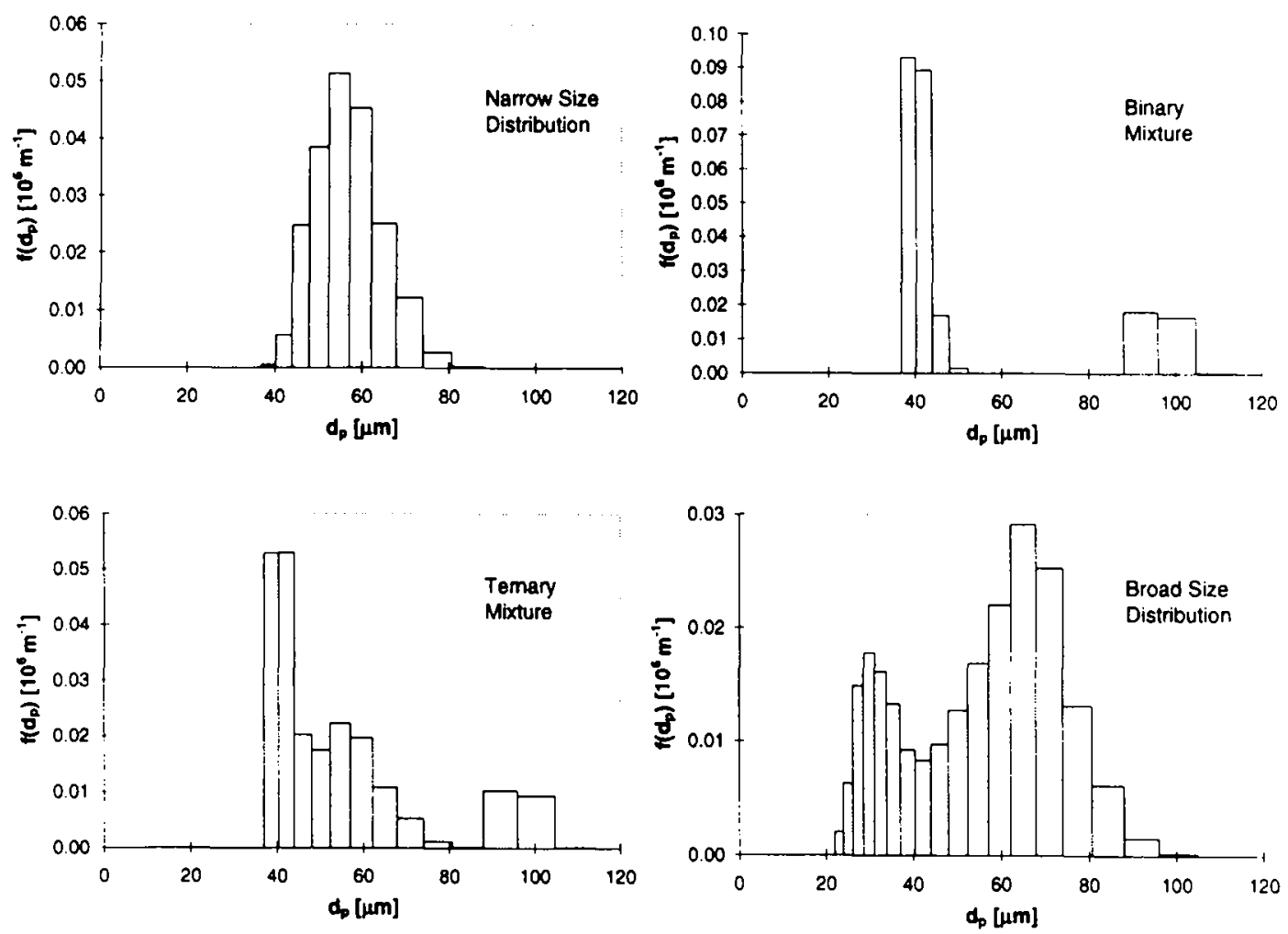

Fig. 5. Probability density functions of applied mixtures calculated from measured cumulative size distribution data.

\section{RESULTS AND DISCLSSION}

\subsection{Maximum resistances}

For the applied loads of particles with a narrow size distribution $(10,15,30,60 \mathrm{~g})$, maximum cake resistance was proven to be directly proportional to load of solids. For $30 \mathrm{~g}$ of particles maximum resistance was proven to be inversely proportional to the square of the series diameter [eq. (9)] of the particle size distributions applied. Assuming a uniform perfectly stratified cake possessing a solidity of 0.63 , all measured maximum resistances could be described by the Kozeny-Carman equation with a maximum error of $3 \%$.

\subsection{Cake ratio}

Similar to the approach taken by Huizenga et al. (1997), cake resistance was scaled by its maximum value to allow direct comparison of the experimental data obtained for solids with different particle size distributions. If the resistance of the cake is a monotonically increasing function of cake volume, the cake ratio (CR) can be regarded as an indirect measure of the volume of solids contained in the slurry bulk. If the latter quantity is an increasing function of solids concentration in the vicinity of the filter, cake ratio can be regarded as an indirect measure for the latter and should therefore depend on the same dimensionless number.

\subsection{Influence of load}

Experimentally determined cake ratios, for the four solids loads applied, are compared with predictions obtained from the monodisperse force balance model in Fig. 6. Both from theory and experiment it follows that at higher solids loads cake ratio starts to increase 


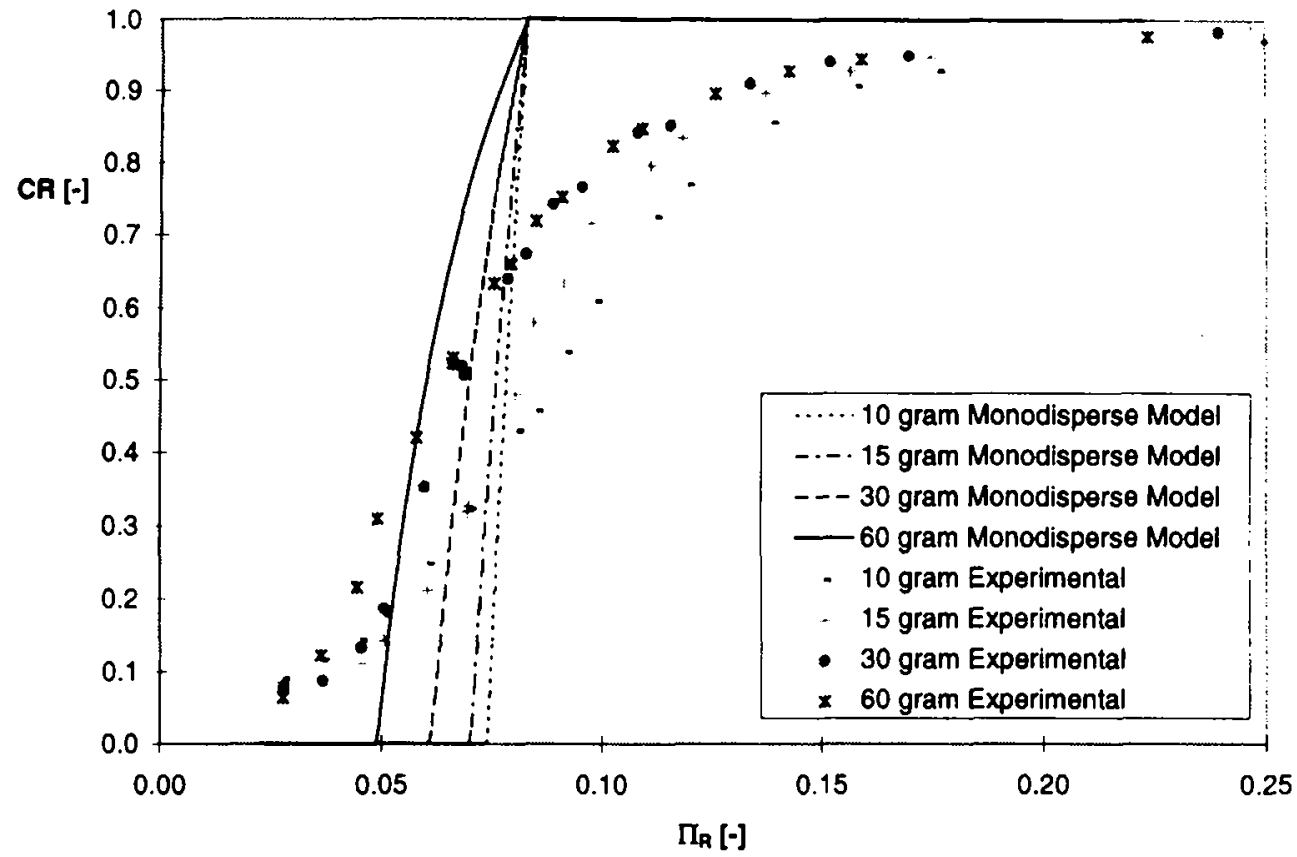

Fig. 6. Experimental and monodisperse force balance model $(\alpha=6.0)$ results for simultaneous variation of gas velocity, permeate flux and load of solids. The dimensionless number has been corrected for crosssectional area reduction [eq. (19)]. $T=29 \mathrm{C}, d_{p, r}=57 \mu \mathrm{m}$, narrow size distribution

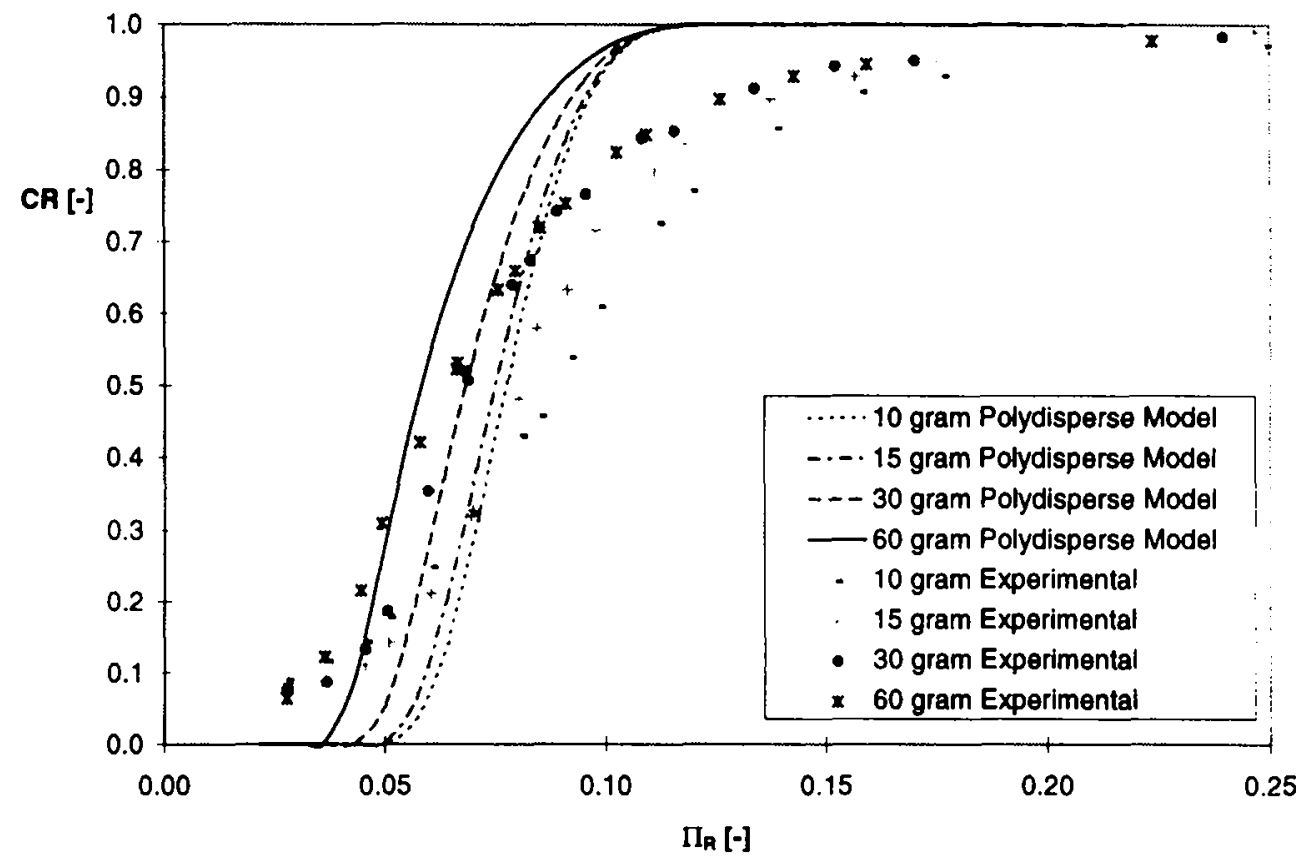

Fig. 7. Experimental and polydisperse force balance model $(x=6.0)$ results for simultaneous variation of gas velocity, permeate flux and load of solids. The dimensionless number has been corrected for crosssectional area reduction [eq. (19)]. $T=29^{\circ} \mathrm{C}, d_{p .1}=57 \mu \mathrm{m}$, narrow size distribution.

at lower values of the cake build-up number $\Pi_{R}$. Theoretically calculated curves are however considerably steeper as compared to those obtained from experiments. Results obtained from the polydisperse model show the same trend with respect to solids load (Fig. 7). Though calculated curves are less steep than those from the monodisperse model, they are still much steeper as compared to their experimental counterparts. In Figs. 6 and 7 gas velocity in the vicinity of the filter has been corrected for 
cross-sectional area reduction due to filter cake formation [Fig. 2(b)]:

$$
U_{g . \mathrm{corr}}=\frac{U_{g}}{a_{b}}
$$

Throughout the article in model calculations a value 6.0 has been assumed for the damping factor, $x$. This value was determined by fitting the polydisperse force balance model to experimental data for $30 \mathrm{~g}$ of glass beads with a narrow size distribution in the vicinity of $\mathrm{CR}=0.5$. Since curves are at their steepest in this region, determination of the unknown constant $\alpha$ is done most accurately this way. The observed value compares well to those found by Davies (1986) and Huizenga et al. (1997).

If the reduction of bulk volume in the filter zone is neglected compared to total bulk volume and further it is assumed that the total mass of solids in the bulk is directly proportional to its concentration in the vicin. ity of the filter, at each value of the cake build-up number there exists a certain equilibrium content of monodisperse solids which is independent of load. Further assuming cake resistance to be directly proportional to cake volume, cake ratio can be seen as the volume fraction of the particles present in the system that is part of the cake. It then follows from a mass balance:

$$
\begin{gathered}
\mathrm{CR}=0 \Rightarrow V^{*} \geqslant \frac{M_{s, \text { tot }}}{\rho_{\mathrm{s}}} \\
\mathrm{CR}>0 \Rightarrow V^{*}=(1-\mathrm{CR}) \frac{M_{\mathrm{s}, \mathrm{tot}}}{\rho_{\mathrm{s}}} .
\end{gathered}
$$

The first part of the above equation expresses that as long as there are no particles in the cake, the bulk can at least contain the volume of solids present in the system. If there are particles present in the cake, the bulk of the system exactly contains its equilibrium content, as presented by the second part of eq. (20). The equilibrium content of solids at a certain value of the cake build-up number as calculated from the above equation for a certain load can now be used to obtain cake ratio at the same cake build-up number at any lower load. After some rearrangement this leads to the following relations for two different loads of solids denoted with subscripts I and II:

$$
\begin{aligned}
& . M_{\text {s.ter.1 }} \geqslant M_{s . \text { tot. II: }}
\end{aligned}
$$

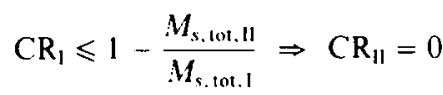

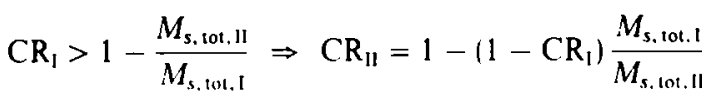

Using the above equation, cake ratio curves for any load can be predicted from results at higher loads. As can be seen from Fig. 8 the transformation works quite well for the monodisperse force balance model as was already observed by Huizenga et al. (1997). If the same transformation is however applied to the experimental results no single curve is obtained. When looking more closely, even inverse trends are observed. The model predictions of the cake ratio vs cake build-up number $\left(\Pi_{R}\right)$ curve at a load of $10 \mathrm{~g}$ from results at higher loads shift to the left with

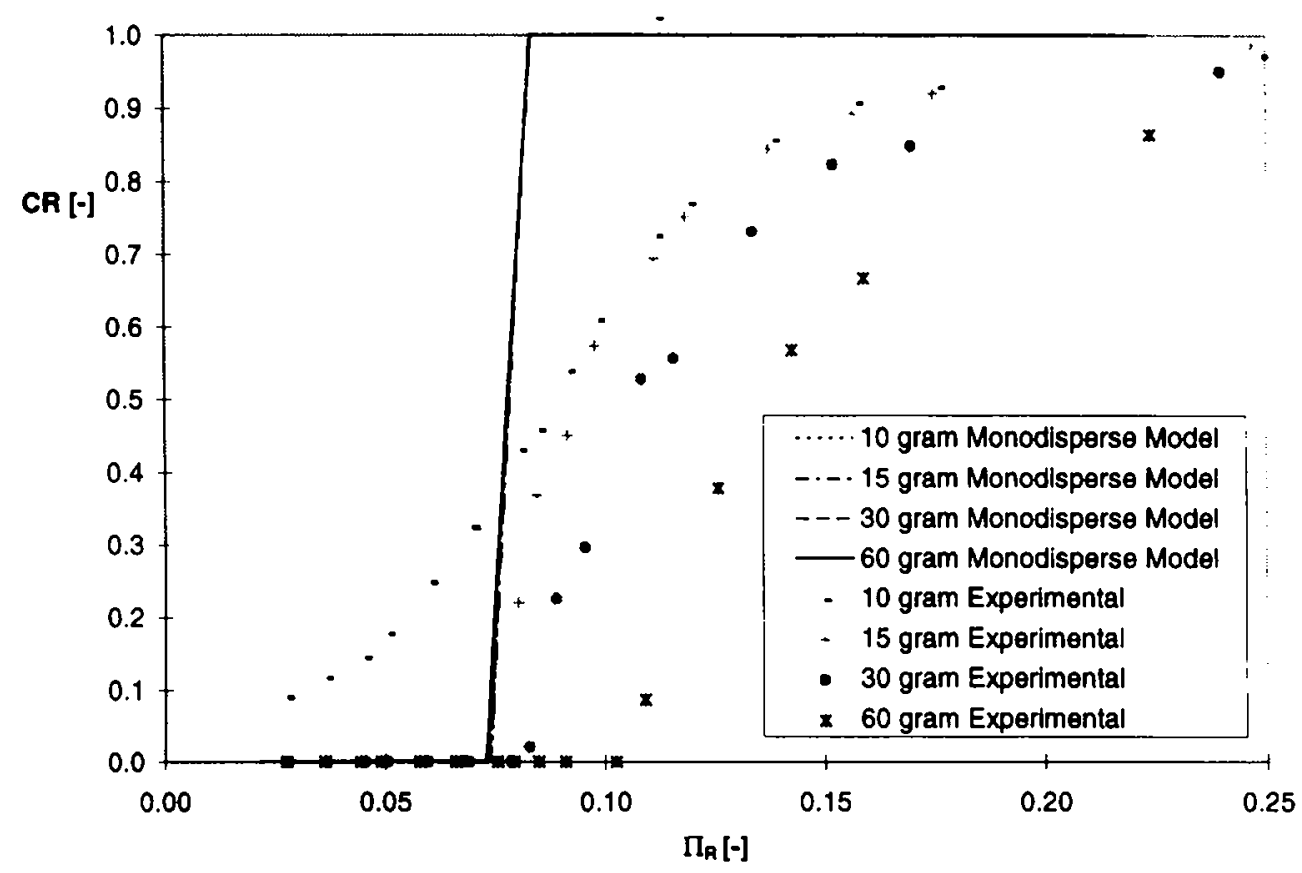

Fig. 8. Effect of mass balance based load transformation [eq. (21)] on experimental and monodisperse force balance model $(x=6.0)$ results. The dimensionless number has been corrected for cross-sectional area reduction [eq. (19)]. $T=29^{\circ} \mathrm{C}, d_{p, r}=57 \mu \mathrm{m}$, narrow size distribution. 


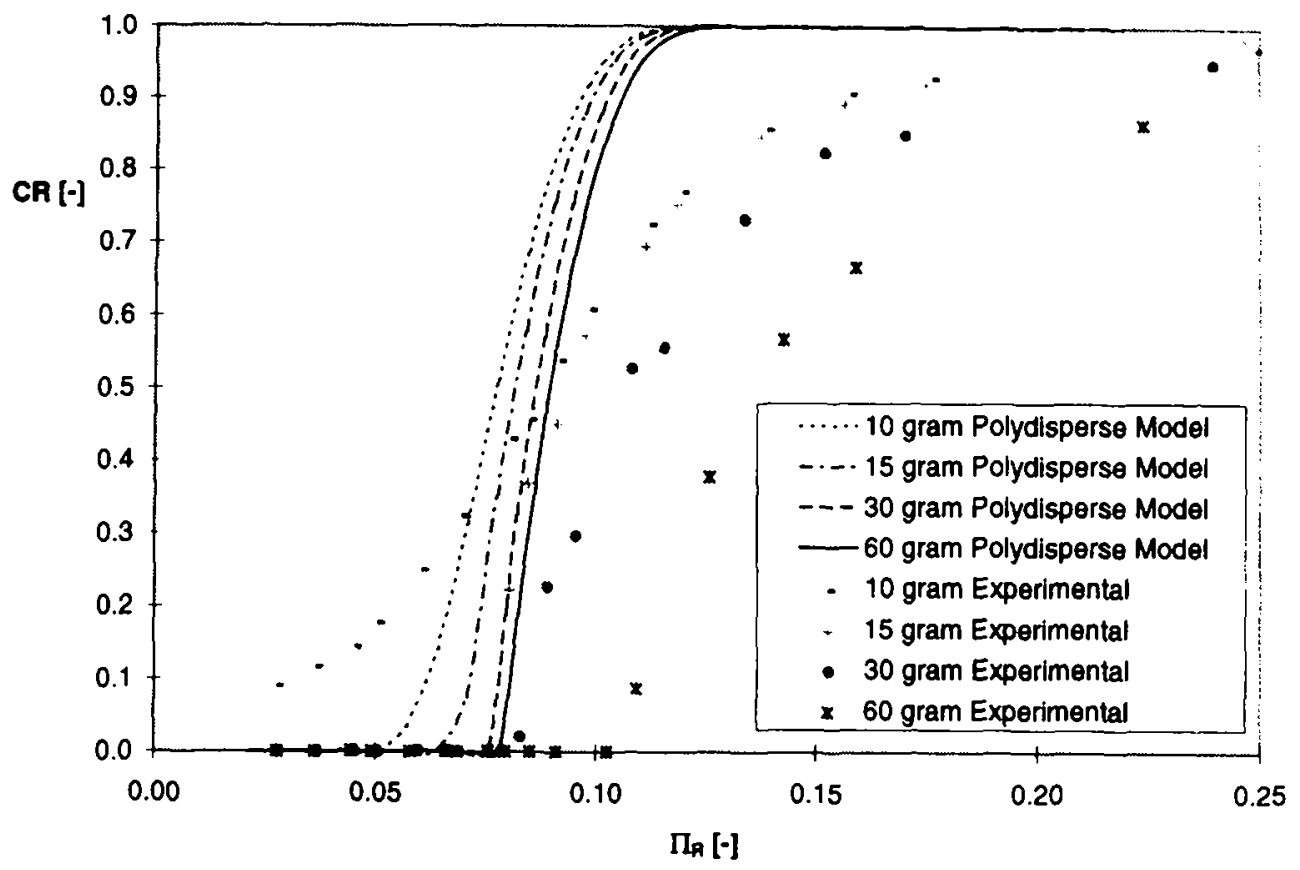

Fig. 9. Effect of mass balance based load transformation [eq. (21)] on experimental and polydisperse force balance model $(x=6.0)$ results. The dimensionless number has been corrected for cross-sectional area reduction [eq. (19)]. $T=29^{\circ} \mathrm{C} . d_{p . t}=57 \mu \mathrm{m}$, narrow size distribution.

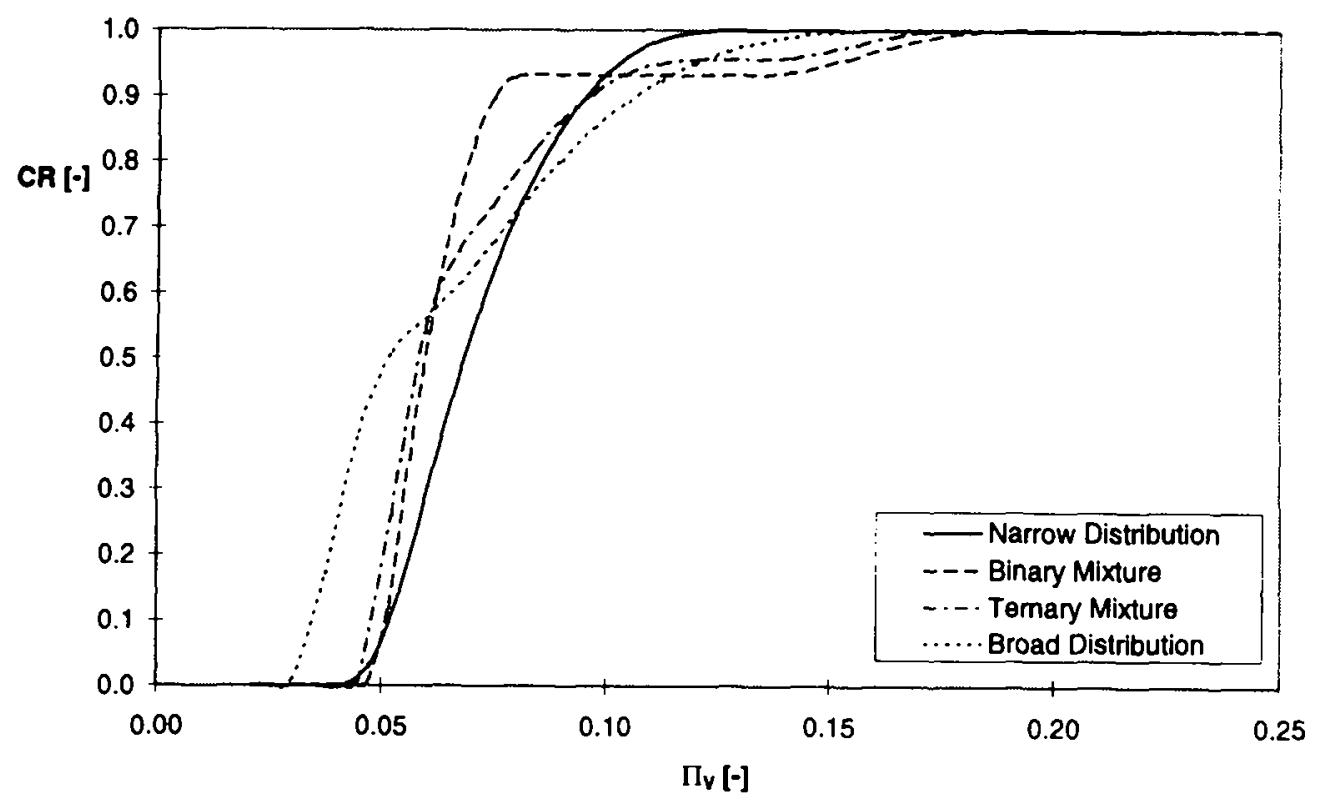

Fig. 10. Cake ratios predicted from the polydisperse force balance model for the $d_{p . t}=57 \mu \mathrm{m}$ distributions used. Volume-mean diameter substituted in the cake build-up number. $T=30^{\circ} \mathrm{C}$, load of solids $=30 \mathrm{~g}$.

increasing load, while they shift in the opposite direction in the transformed experimental results. If however particle polydispersity is taken into account the experimentally observed trend agrees with the model results (Fig. 9). Also in Fig. 8 and 9 gas velocity has been corrected for cross-sectional area reduction due to cake formation [eq. (19)].
The trend observed in the polydisperse model can be explained as follows: According to the above equation [eq. (21)] the prediction of the cake ratio vs cake build-up number curve at a load of $10 \mathrm{~g}$ from results at a load of $60 \mathrm{~g}$ depends on the particles responsible for the final $1 / 6$ of the resistance at the latter load. For polydisperse suspensions cake resistance is not 


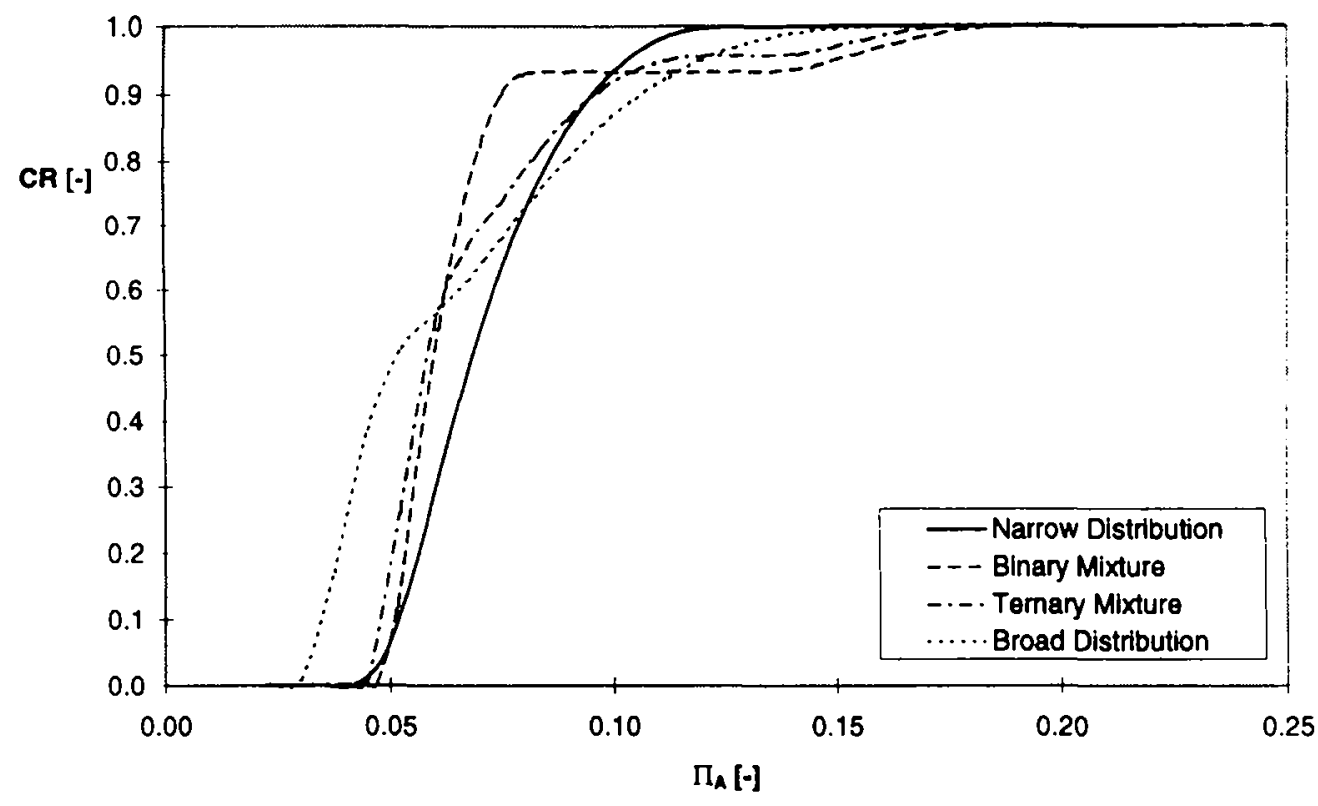

Fig. 11. Cake ratios predicted from the polydisperse force balance model for the $d_{p . \mathrm{r}}=57 \mu \mathrm{m}$ distributions used. Area-mean diameter substituted in the cake build-up number. $T=30^{\circ} \mathrm{C}$. load of solids $=30 \mathrm{~g}$.

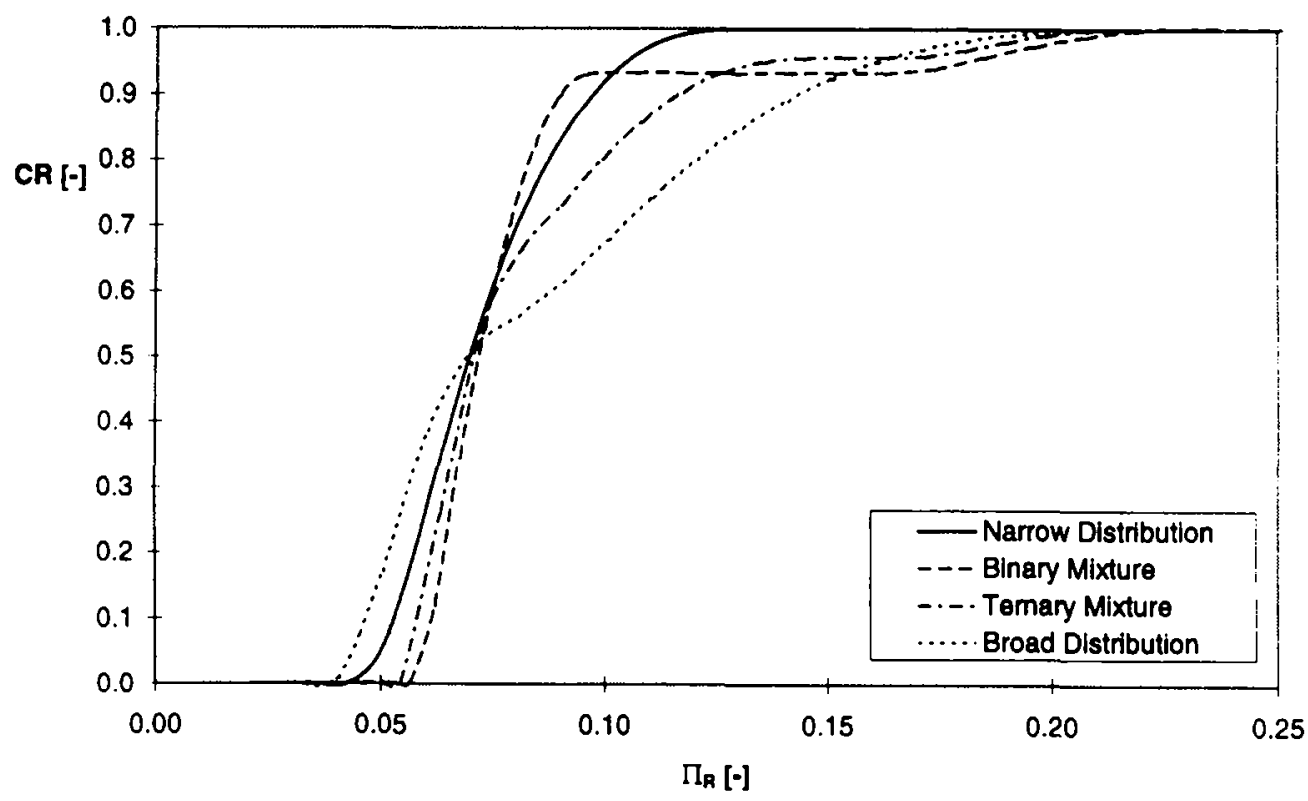

Fig. 12. Cake ratios predicted from the polydisperse force balance model for the $d_{p, c}=57 \mu \mathrm{m}$ distributions used. Resistance diameter [eq. (11)] substituted in the cake build-up number. $T=30^{\circ} \mathrm{C}$, load of solids $=30 \mathrm{~g}$.

directly proportional to cake volume and average particle size in the suspension varies with cake ratio. Relatively large particles present in a suspension deposit at higher cake build-up numbers based on resistance diameter $\Pi_{R}$ than smaller particles, since the cake build-up number based on their size is lower. Specific resistance is known to decrease with particle diameter. Therefore, the final $1 / 6$ of the resistance of $60 \mathrm{~g}$ consists of a larger volume of solids of a larger average diameter as compared to $10 \mathrm{~g}$ of particles. The former effect may lead to higher solids concentrations and therefore to deposition at lower cake buildup numbers $\Pi_{R}$ as compared to $10 \mathrm{~g}$ of particles. The increase in size however leads to deposition at higher dimensionless numbers $\Pi_{R}$ as compared to $10 \mathrm{~g}$ of particles and this evidently is the predominant effect leading to the observed agreement with the trend from experiments (Fig. 9). 


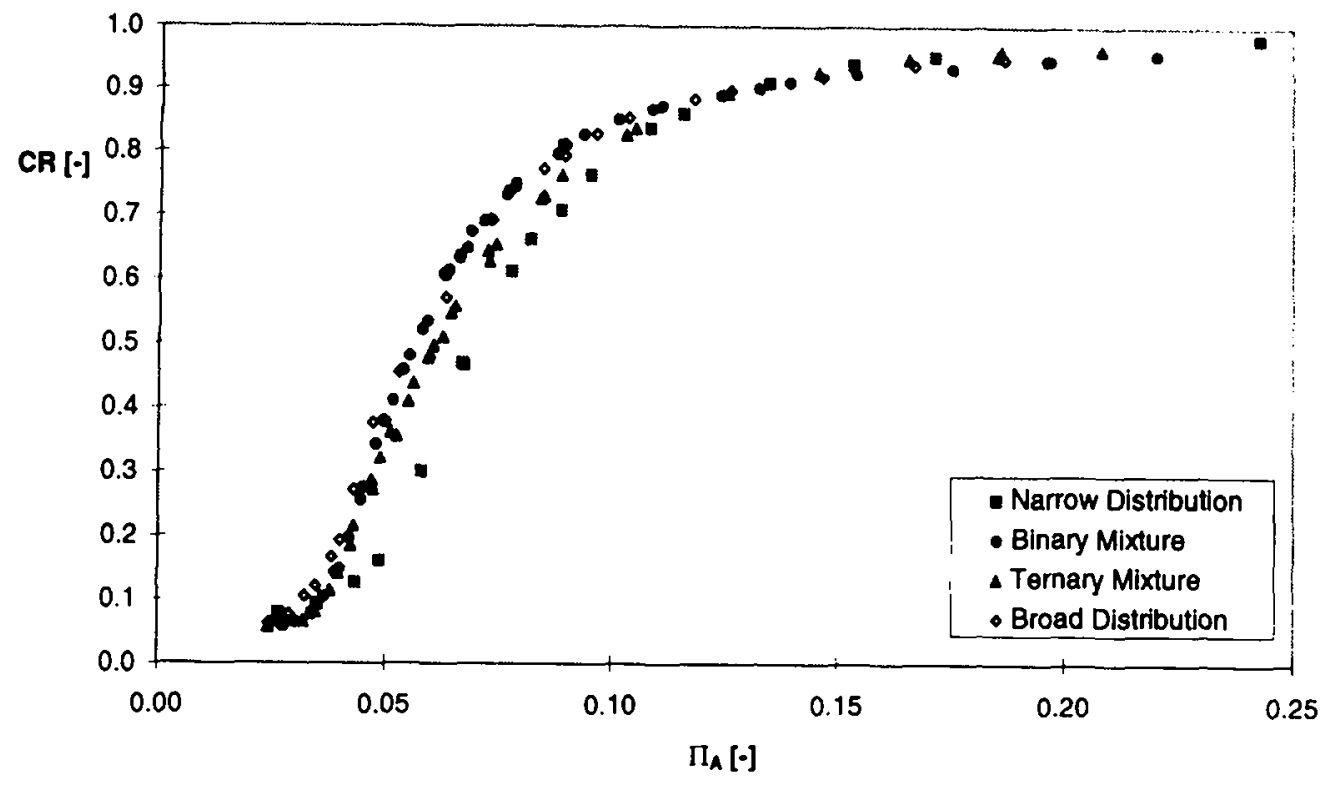

Fig. 13. Measured cake ratios for four different $d_{p . v}=57 \mu \mathrm{m}$ distributions. Area-mean diameter substituted in the cake build-up number. $T=30^{\circ} \mathrm{C}$, load of solids $=30 \mathrm{~g}$.

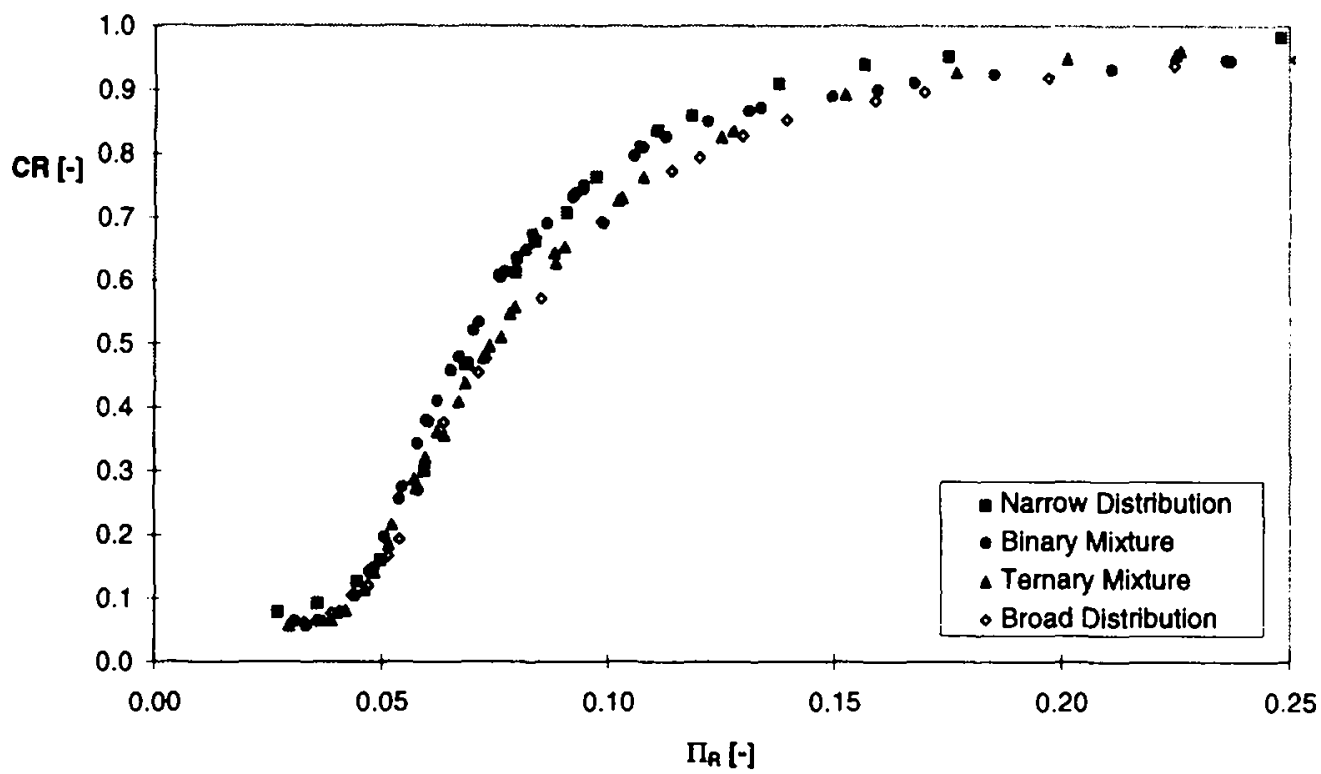

Fig. 14. Measured cake ratios for four different $d_{p . t}=57 \mu \mathrm{m}$ distributions. Resistance diameter [eq. (11)] substituted in the cake build-up number. $T=30^{\circ} \mathrm{C}$, load of solids $=30 \mathrm{~g}$.

\subsection{Influence of particle size distribution}

Calculated cake ratio vs cake build-up number curves obtained from the polydisperse force balance model can be found in Figs 10-12. These three figures differ with respect to the characteristic diameter sub. stituted in the cake build-up number. It can be observed that the curve of the narrow size distribution for a considerable part lies to the right of the other curves if volume- or area-mean diameter is substituted. If however resistance diameter [eq. (11)] is substituted, this is no longer the case and calculated curves intersect in the vicinity of $C R=0.5$, as predicted from the step function model. Data calculated upon substitution of series diameter [eq. (9)] are not shown since they show similar trends as observed when area-mean diameter was substituted.

Experimentally determined curves show the same trend with respect to diameter substituted (Fig. 13 and 14). The intersection at $C R=0.5$, as predicted from the step function model can however not be observed (Fig. 14), although experiments can be described reasonably well by a single curve upon substitution of 
resistance diameter. It can also be observed in Fig. 14 that the curve with the narrowest distribution approaches the condition of maximum cake build-up $(C R=1)$ at lower cake build-up numbers as predicted by the polydisperse force balance model (Fig. 11).

Though qualitative agreement between trends observed from model and experiments exists, the experimental curves are still considerably broader than those theoretically calculated. This may be explained by the neglect of the influence of filter length. Solids concentration is in fact a function of axial position. Therefore, locally the flux may be high enough for cake formation, though it is not on average. The opposite may also be true. Both effects may contribute considerably to the broadness of the curve based on average values.

\section{CONCLUSION}

Incorporation of polydispersity in the force balance model broadens the calculated curves of cake ratio vs cake build-up number. Calculated curves are however still considerably steeper than those obtained from experiments. Though results from the monodisperse force balance model at lower loads can be calculated from those at higher loads using a mass balance-based transformation. this is not the case for the experimental results. If the effect of particle polydispersity is taken into account, the experimentally observed trend is however reproduced.

Qualitative agreement between experimentally observed trends upon variation of particle size distribution and results from the polydisperse force balance model has been demonstrated. Quantitative discrepancies may be attributed to the neglect of the influence of filter length.

\section{Acknowledgements}

These investigations were supported by the Dutch Research School for Process Technology (OSPT). The authors also acknowledge $W$. Leppink for his technical support and M.G. Eltink for his contribution to the experimental work.

\section{NOTATION}

$a_{h}$ slurry fraction of cross-sectional area in filter zone, dimensionless

$A_{\text {fidt }} \quad$ permeable area used for filtration. $\mathrm{m}^{2}$

$C$ : parameter of the probability distribution function [eq. (18)], dimensionless

CR cake ratio ( = ratio of actual and maximum cake resistance), dimensionless

$d_{p} \quad$ particle diameter, $m$

$d_{p, \min } \quad$ lower boundary of particle size range, $m$

$d_{p, \max }$ upper boundary of particle size range, $m$

$D_{\mathrm{ax} . \mathrm{s}} \quad$ solids axial dispersion coefficient, $\mathrm{m}^{2} \mathrm{~s}^{-1}$

$E$ energy dissipation rate per unit mass of liquid-solid slurry, $\mathrm{m}^{2} \mathrm{~s}^{-3}$

$f\left(d_{p}\right) \quad$ volume probability density function, $\mathrm{m}^{-1}$

$f(z) \quad$ volume probability density function [eq. (17)], dimensionless

$F\left(d_{p}\right)$ cumulative size distribution function, $\mathrm{m}^{-1}$

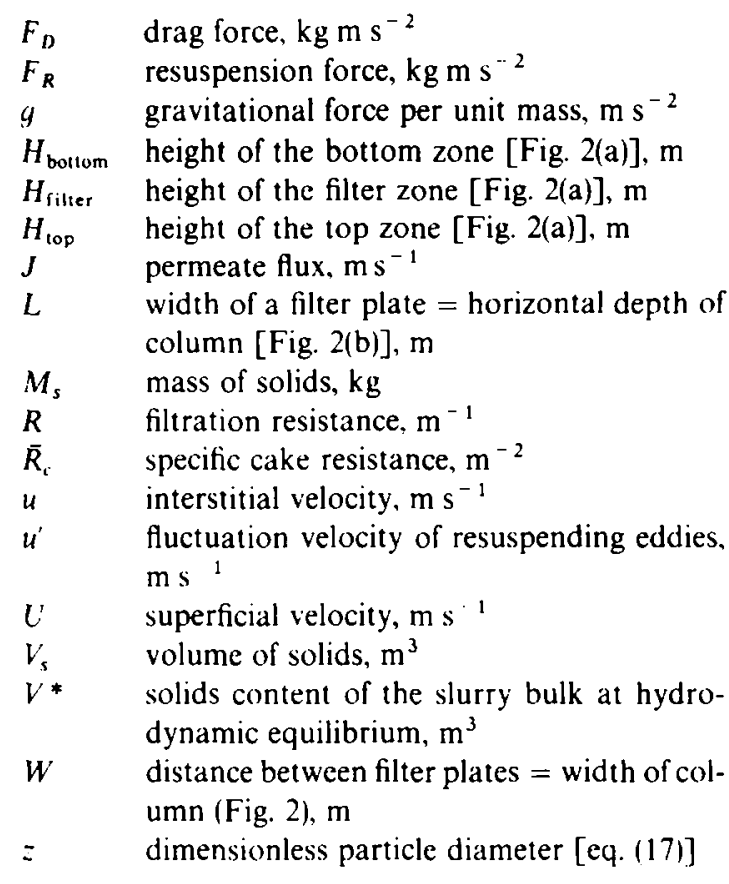

\section{Greek letters}

$x$ damping factor, dimensionless

ic cake thickness, $m$

$\varepsilon_{g} \quad$ gas volume fraction $[=1-$ volume fraction of slurry)], dimensionless

$i_{s} \quad$ volume fraction solids in slurry $[=1-($ volume fraction of liquid in slurry)], dimensionless

$\eta \quad$ dynamic viscosity, $\mathrm{kg} \mathrm{m}^{-1} \mathrm{~s}^{-1}$

$i \quad$ length scale, $m$

$\mu_{z} \quad$ parameter of the probability density function [eq. (18)], dimensionless

r. kinematic viscosity, $\mathrm{m}^{2} \mathrm{~s}^{1}$

$\rho$ density, $\mathrm{kg} \mathrm{m}^{-3}$

$\begin{array}{ll}\text { Subscripts } \\ a & \text { area-mean (particle diameter) } \\ b & \text { bulk property } \\ c & \text { cake property } \\ g & \text { gas phase } \\ k & \text { Kolmogoroff } \\ l & \text { liquid phase } \\ \text { max } & \text { maximum value } \\ p & \text { particle } \\ r & \text { resistance (particle diameter) } \\ s & \text { solid phase } \\ s & \text { series (particle diameter) } \\ s l & \text { liquid-solid slurry property } \\ r & \text { volume-mean (particle diameter) } \\ \text { tot } & \text { total amount present in the batch of solids }\end{array}$

\section{Superscript}

* equilibrium

Dimensionless group

$\Pi \quad$ cake build-up number $\left[=\left(J i d_{p}\right) \sqrt{v_{1} / U_{g}^{\prime} g}\right]$ 


\section{REFERENCES}

Darton, R. C. (1984) Hydrodynamics, heat and mass transfer in three-phase fluidized beds, Proceedings XVIth ICHMT Symposium on Heat and Mass Transfer in Fixed and Fluidized Beds, Dubrounik, Yugoslavia.

Davies, J. T. (1986) Particle suspension and mass transfer in agitated vessels. Chem. Engng Process. 20, 175-181.

Deckwer, W. D., Louisi, Y., Zaidi, A. and Ralek, M. (1980) Hydrodynamic properties of the FischerTropsch slurry process. Ind. Engng Chem. Process. Des. Dev. 19, 699-708.

Foley, G., Malone, D. M. and MacLoughlin, F. (1995) Modelling the effects of particle polydispersity in crossflow filtration. J. Membrane $S c i$. 99, 77-88.

Huizenga, P., Kuipers, J. A. M. and van Swaaij, W. P. M. (1997) Description of three-phase filtration with a novel dimensionless number, A.I.Ch.E.J. (submitted).

Jager, B., Steynberg, A. P., Inga, J. R., Kelfkens, R. C., Smith, M. A. and Malherbe, F. E. J. (1994) Process for producing liquid and, optionally gaseous products from gaseous reactants. Sasol Chemical
Industries Ltd., Johannesburg, South Africa, EP 00609079 Al.

Kato, Y., Nishiwaki, A., Fukuda, T. and Tanaka, S. (1972) The behavior of suspended solid particles and liquid in bubble columns. J. Chem. Engng Jpn 5, $112-118$

Kraft, A. and Mende, U. (1995) Niedrigenergie-Membranverfahren zum Biomassenrückhalt in Abwasserreinigungsanlagen. Filt. Sep. 9, 245-254.

Peleg, M., Normand, M. D. and Rosenau, J. R. (1986) A distribution function for particle populations having a finite size range and a mode independent of the spread. Powder Technol. 46, 209-214.

Rytter, E., Roterud, P., Lian, P. and Myrstad, T. (1994) Solid-liquid slurry treatment apparatus and catalytic multi-phase reactor. Den Norske Stats Oljeselskap A.S., Stavanger (Norway), WO 94; 16807.

Smith, D. N., Ruether, J. A., Shah, Y. T. and Badgujar, M. N. (1986) Modified sedimentation-dispersion model for solids in a three-phase slurry column. A.I.Ch.E. J. 32, 426-436.

Wen, C. Y. and Yu, Y. H. (1966) Mechanics of fluidization. Chem. Engng Progr. Symp. Ser. 62, 100-111. 